\title{
Factors affecting compliance and control of asthma in patients attending the Respiratory Outpatient Department, Chris Hani Baragwanath Academic Hospital
}

\author{
S A van Blydenstein, ${ }^{1} \mathrm{MB}$ BCh, FCP(SA), MMed (Int Med), DCh (SA); L Nqwata, ${ }^{1}$ MB ChB (WSU), FCP (SA); \\ N P K Banda, ${ }^{1}$ MBBS, MMed; P Ashmore, ${ }^{2}$ BSc (Hons), MBBS, FCP (SA), MMed (Int Med); \\ M L Wong, ${ }^{1}$ MB BCh, DCh (SA), FCP (SA), FCCP, FRCP (Lond)
}

\begin{abstract}
${ }^{1}$ Division of Pulmonology, Chris Hani Baragwanath Academic Hospital and Faculty of Health Sciences, University of the Witwatersrand, Johannesburg, South Africa ${ }^{2}$ Division of Haematology, Chris Hani Baragwanath Academic Hospital and Faculty of Health Sciences, University of the Witwatersrand, Johannesburg, South Africa
\end{abstract}

Corresponding author: S A van Blydenstein (savanblydenstein@gmail.com)

Background. There is a sense among respiratory physicians that asthma is poorly controlled in public sector hospitals, possibly due to poor adherence and lack of knowledge regarding inhaler technique.

Objective. To describe the status of asthma control in patients attending the Respiratory Outpatient Department at Chris Hani Baragwanath Academic Hospital.

Methods. A retrospective record review was conducted on outpatient files of asthmatics known to the Respiratory Department. Data obtained included demographics, level of control and number of admissions and exacerbations.

Results. A total of 519 patient files were reviewed, $74.2 \%$ of whom were female. The mean (standard deviation) age was 47 (16.5) years. We found $47.2 \%$ of patients were controlled, $30.4 \%$ partially controlled and $22.4 \%$ uncontrolled. Most patients ( $88 \%$ ) had no admissions in the previous year. About $60 \%$ had not experienced exacerbations in the previous year. There were significant differences between the three groups for number of exacerbations, both per year and per lifetime, and type of steroid prescribed. For a number of significant areas, such as forced expiratory volume in one second $\left(\mathrm{FEV}_{1} \%\right)$ predicted and competency of inhaler technique, a large proportion of the data $(>30 \%)$ had not been documented by the attending doctor in the patient files.

Conclusion. In this population of mostly middle-aged female asthmatics, less than half the patients were well-controlled despite very few admissions or exacerbations in the previous year. Documentation by clinicians of aspects indicative of asthma control was generally poor, and better documentation should be encouraged in order to improve knowledge and highlight awareness of best practice in the management of asthma.

S Afr Respir J 2015;21(4):91-95. DOI:10.7196/SARJ.2015.v21i4.43

Asthma is a chronic, inflammatory airway disease involving airway hyper-responsiveness and intermittent airflow obstruction. Although potentially under-reported, asthma affects $20 \%$ of people in sub-Saharan Africa. ${ }^{[1]}$ There is a wide range in prevalence among different geographic locations, owing in part to poverty, climate, and allergen exposure. ${ }^{[1]}$ There appears to be a racial discrepancy in prevalence of asthma, with Asians being less affected than Native Americans, and a gender discrepancy, with a female preponderance among adult asthmatics. ${ }^{[2]}$ Patients with asthma over the age of 65 years tend to fare worse than younger patients. ${ }^{[3]}$

Identification of the level of severity of asthma and determination of the factors affecting asthma control are crucial to the design and implementation of strategies to reduce the number of exacerbations and hospital admissions, thus improving outcomes. Of vital importance is the documentation of important parameters in the management of asthma, particularly in a public hospital where patients often see different doctors at each visit. These include inhaler technique, frequency of exacerbations and number of admissions to hospital.

Our impression is that the control of asthma in patients attending the Respiratory Outpatient Department (ROPD) at Chris Hani
Baragwanath Academic Hospital (CHBAH), Johannesburg, is suboptimal. However, no study has been performed at our hospital to interrogate this hypothesis, or to quantify the proportion of our patients with severe disease and/or poor control. We are of the opinion that these data will provide important information on asthma management relevant to the South African (SA) healthcare system.

\section{Methods}

We undertook a retrospective analysis of scheduled visits by patients with asthma attending the ROPD at CHBAH. Data collected included demographics, symptoms, disease severity, medication prescription and usage, control of asthma, inhaler technique competency and spirometry. This information was captured by the investigator using a data collection sheet that is routinely completed as part of our patients' clinic records. The sources of information were the patients' files, held at ROPD.

Definitions of asthma control and indicators of asthma severity were based on those advocated by local SA Thoracic Society guidelines. ${ }^{[4]}$ Acute exacerbations and severity were determined by the need for oral steroid use, days off work, antibiotic use, number of Emergency Department visits (exacerbations), intensive care unit admissions and general ward 
admissions due to asthma in the prior 12 months. Examination findings and spirometry results were also captured. Age, gender and comorbidities were noted in an attempt to identify any factors that were associated with poor control or severity of asthma. Treatment prescriptions were documented, as well as any comments regarding use of medication in the previous month. The diagnosis of asthma was based on clinical assessment. The diagnosis of gastro-oesophageal reflux was based on either reporting of symptoms, barium swallow or gastroscopy. Any patient $\geq 18$ years known to have asthma who presented for a scheduled visit to ROPD within the defined period was included.

Patient demographics and clinical characteristics of the cohort group were summarised using descriptive statistics. All categorical data were analysed using the $\chi^{2}$-test, unless the frequency was $\leq 5$, in which case Fisher's exact test (two-tailed) was used. Student's $t$-test was used for numerical variables when comparing well-controlled asthmatics with poorly controlled asthmatics.

Ethical approval was obtained from the Human Research Ethics Committee (Medical) of the University of the Witwatersrand (M150458), and from the CHBAH Medical Advisory Committee.

\section{Results}

A total of 586 patient files were reviewed. Sixty patients were younger than 18 years of age, leaving 526 eligible for analysis. Of these, a further 7 were excluded as their level of control was not determined. Of the study population, $74.2 \%$ were female. The median (standard deviation (SD)) age was 46 (16.5) years. With regard to levels of asthma control, $47.2 \%(245 / 519)$ were controlled, $30.4 \%$ were partially controlled (158/519), and $22.4 \%$ were uncontrolled (116/519). There was no significant difference in terms of age and median forced expiratory volume in one second $\left(\mathrm{FEV}_{1}\right)$ /forced expiratory vital capacity (FVC) between the controlled, partially controlled and uncontrolled groups (Table 1). The controlled group, however, had statistically significantly higher percent predicted and median $\mathrm{FEV}_{1} \%$ than the partially controlled and uncontrolled groups $(p<0.05)$.

The risk posed to asthma control by hospital admissions is shown by the fact that the number of admissions per year was lowest in the controlled group, compared with the uncontrolled (odds ratio (OR) 8.14, $p<0.0001$ ), and the partially controlled groups (OR 3.99, $p<0.0001$ ) (Table 2). Only the uncontrolled group had significantly more admissions per lifetime than the controlled group (OR 2.4, $p=0.0025$ ). There were similar differences in the acute exacerbations whether determined per week or per year between the controlled, partially controlled and uncontrolled groups of patients.

In almost half the cases, doctors did not document the patients' inhaler technique (Table 2). Doctors assessed patients' inhaler technique as 'fair to good' in only 59 partially controlled and 31 uncontrolled asthmatics v. the controlled group, which was significantly different from the uncontrolled group (Table 2).

The uncontrolled patients were also statistically more likely to be prescribed both inhaled and oral corticosteroids (CSs) than the controlled group (Table 2).

In all three groups of asthma control there was a median of one comorbidity. Fig. 1 illustrates the variety of comorbidities found in the cohort, and the numbers found within the levels of asthma control.

There were no significant differences between levels of asthma control for patients with co-existent gastro-oesophageal reflux disease
(GERD), eczema, hypertension, diabetes mellitus, HIV infection, heart disease, depression and other psychiatric disorders, and obesity. There was a significant difference in asthma control in patients with co-existent rheumatoid arthritis, allergic rhinitis and previous tuberculosis. Rheumatoid arthritis was more frequent in those patients with controlled asthma compared with uncontrolled $(p=0.018)$ and partially controlled asthma $(p=0.032)$. Allergic rhinitis was also more commonly diagnosed in the controlled group compared with the partially controlled group ( $p=0.023$ ). Previous tuberculosis was more common in the partially controlled group than the controlled group $(p=0.020)$ (Table 3$)$.

\section{Discussion}

Our data show that a large number of adult asthmatic patients attending the ROPD at CHBAH hospital remain either partially controlled or uncontrolled. Our patients were mainly middleaged women with one comorbidity. The level of asthma control is associated with \%-predicted and median $\mathrm{FEV}_{1}$, number of admissions and exacerbations and steroid use.

The overwhelming preponderance (74.2\%) of female asthmatics attending our clinic was somewhat surprising. A higher incidence of asthma among females in the adult population is described ${ }^{[5-7]}$ yet our figures are higher than generally reported. We are a tertiary level facility, and preferentially follow up patients whose asthma is difficult to control. The cluster analysis study of severe asthma (Moore et $a{ }^{[8]}$ ) also found that women constituted the majority in all five cluster phenotypes, although the proportions ranged from $53 \%$ to $80 \%$. Females may have greater health-seeking behaviour than men ${ }^{[9]}$ This phenomenon remains an area for further study.

The median (SD) age was 47 (16.5) years, with no significant age difference between the groups stratified by the three levels of control. This is likely a reflection of the catchment population, but is also in keeping with other studies. ${ }^{[7]}$

Occupational asthma in adults, as is described by Burney et al., ${ }^{[10]}$ was unfortunately not examined in this study, as we did not record employment or type of occupation. We are thus unable to comment on the relative contribution that occupational asthma plays in the prevalence of asthma in our adult population.

We found that the majority of our patients were either partially controlled or uncontrolled, similar to the findings of an American study which showed that $74 \%$ of patients were partially controlled or uncontrolled (according to GINA guidelines). ${ }^{[11]}$ A recent Italian study demonstrated that only $9.1 \%$ of asthmatics were controlled ${ }^{[7]}$ and in an SA study, Mash et al..$^{[12]}$ reported that only $31.5 \%$ of asthmatics in the Western Cape were controlled.

The median $\mathrm{FEV}_{1}$, when expressed as a percentage of predicted, decreased with the level of control. This trend was echoed by the absolute $\mathrm{FEV}_{1}(\mathrm{~L})$. However, the $\mathrm{FEV}_{1} / \mathrm{FVC}$ ratio was not significantly different between the groups stratified by level of control. A possible explanation for this unchanged ratio could be a persistent airflow limitation. In a number of patients, the data were obtained from spirometry values documented by the attending doctor, and the flow volume curves were not examined by the investigator.

Most patients (77.2\%) had had no admissions in the previous year, and $60.1 \%$ had not experienced exacerbations in the previous year. Predictably, the poorer the control, the more admissions patients were 
Table 1. Patient characteristics

\begin{tabular}{|c|c|c|c|c|c|c|}
\hline & Total group & $\begin{array}{l}\text { Well-controlled } \\
(N=245)\end{array}$ & $\begin{array}{l}\text { Partially } \\
\text { controlled } \\
(N=158)\end{array}$ & $\begin{array}{l}\text { Well-controlled } \\
\text { v. partially } \\
\text { controlled }\end{array}$ & $\begin{array}{l}\text { Uncontrolled } \\
(N=116)\end{array}$ & $\begin{array}{l}\text { Well-controlled v. } \\
\text { uncontrolled }\end{array}$ \\
\hline Age (years), median (SD) & $47(16.5)$ & 45 (17.9) & $48(15.6)$ & NS & $46(14.8)$ & NS \\
\hline Gender (male/female), $n$ & $134 / 385$ & $79 / 166$ & $32 / 126$ & $\begin{array}{l}p=0.012 ; \\
\text { OR } 0.54 ; \\
95 \% \text { CI } 0.33-0.86\end{array}$ & $23 / 93$ & $\begin{array}{l}p=0.02 ; \\
\text { OR } 0.52 ; \\
95 \% \text { CI } 0.31-0.88\end{array}$ \\
\hline $\mathrm{FEV}_{1} \%$ predicted, median $(\mathrm{SD})$ & $81(24.9)$ & $85(24.4)$ & $79(24.1)$ & 0.015 & $70(24.7)$ & 0.000 \\
\hline $\mathrm{FEV}_{1}(\mathrm{~L})$, median $(\mathrm{SD})$ & $1.8(1.8)$ & $2.0(2.4)$ & $1.7(0.7)$ & 0.010 & $1.6(0.7)$ & 0.001 \\
\hline $\mathrm{FEV}_{1} / \mathrm{FVC}$, median (SD) & $72(13.5)$ & $72.5(13.0)$ & $72(13.0)$ & NS & $70.5(15.2)$ & NS \\
\hline
\end{tabular}

Table 2. Factors associated with levels of asthma control

\begin{tabular}{|c|c|c|c|c|c|c|c|c|c|}
\hline & \multirow{2}{*}{$\begin{array}{l}\text { Controlled } \\
(N=245), n \\
(\%)\end{array}$} & \multirow{2}{*}{$\begin{array}{l}\text { Partially } \\
\text { controlled } \\
(N=158), n \\
(\%)\end{array}$} & \multirow{2}{*}{$\begin{array}{l}\text { Uncontrolled } \\
(N=116), n \\
(\%)\end{array}$} & \multicolumn{3}{|c|}{ Controlled v. uncontrolled } & \multicolumn{3}{|c|}{$\begin{array}{c}\text { Controlled v. partially } \\
\text { controlled }\end{array}$} \\
\hline & & & & $p$-value & OR & 95\% CI & $p$-value & OR & 95\% CI \\
\hline \multicolumn{10}{|c|}{$\begin{array}{l}\text { Patients with admissions } \\
\text { per lifetime }\end{array}$} \\
\hline None & $84(34.3)$ & $39(24.7)$ & $20(17.2)$ & 0.0031 & 2.5 & $1.39-4.51$ & 0.25 & 1.39 & $0.84-2.29$ \\
\hline Any & $94(38.4)$ & $59(37.3)$ & $56(48.3)$ & & & & & & \\
\hline Unknown & $67(27.3)$ & $60(38)$ & $40(34.5)$ & & & & & & \\
\hline \multicolumn{10}{|l|}{$\begin{array}{l}\text { Patients with an } \\
\text { admission prior year }\end{array}$} \\
\hline None & $209(85.3)$ & $110(69.6)$ & $61(52.6)$ & $<0.0001$ & 8.16 & $4.55-14.93$ & $<0.0001$ & 3.71 & $2.09-6.59$ \\
\hline At least one & $21(8.6)$ & $41(25.9)$ & $50(43.1)$ & & & & & & \\
\hline Unknown & $15(6.1)$ & $7(4.4)$ & $5(4.3)$ & & & & & & \\
\hline \multicolumn{10}{|c|}{ Patients with AE last year } \\
\hline None & $173(70.6)$ & $58(36.7)$ & $13(11.2)$ & $<0.0001$ & 16.79 & $8.50-33.18$ & $<0.0001$ & 4.73 & $2.90-7.72$ \\
\hline One or more & $45(18.4)$ & $57(36.1)$ & $60(51.7)$ & & & & & & \\
\hline Unknown & $27(11.0)$ & $43(27.2)$ & $43(37.1)$ & & & & & & \\
\hline \multicolumn{10}{|c|}{ Patients with AE per week } \\
\hline None & $218(89.0)$ & $93(58.9)$ & $30(25.9)$ & $<0.0001$ & 6.78 & $3.23-14.22$ & $<0.0001$ & 6.93 & $3.46-13.90$ \\
\hline One or more & $12(4.9)$ & $40(25.3)$ & $62(53.4)$ & & & & & & \\
\hline Unknown & $15(6.1)$ & $25(10.2)$ & $24(20.7)$ & & & & & & \\
\hline \multicolumn{10}{|c|}{$\begin{array}{l}\text { Patient inhaler technique } \\
\text { recorded }\end{array}$} \\
\hline Not checked & $155(63.3)$ & $78(49.4)$ & $68(58.6)$ & & NS & & 0.008 & 1.77 & $1.18-2.65$ \\
\hline Checked & $90(36.7)$ & $80(50.6)$ & $48(41.4)$ & & & & & & \\
\hline \multicolumn{10}{|l|}{$\begin{array}{l}\text { Quality of inhaler } \\
\text { technique }\end{array}$} \\
\hline Fair to good & $76(31.0)$ & $59(37.3)$ & $30(25.9)$ & 0.041 & 2.41 & $1.1-5.27$ & & NS & \\
\hline Poor & $14(5.7)$ & $21(13.3)$ & $18(15.5)$ & & & & & & \\
\hline Unknown & $155(63.3)$ & $78(49.4)$ & $68(58.6)$ & & & & & & \\
\hline \multicolumn{10}{|l|}{ CS use } \\
\hline Inhaled plus oral CS ${ }^{*}$ & $54(22.0)$ & $50(31.6)$ & $51(44.0)$ & $<0.0001$ & 2.83 & $1.76-4.55$ & 0.035 & 1.67 & $1.06-2.62$ \\
\hline
\end{tabular}




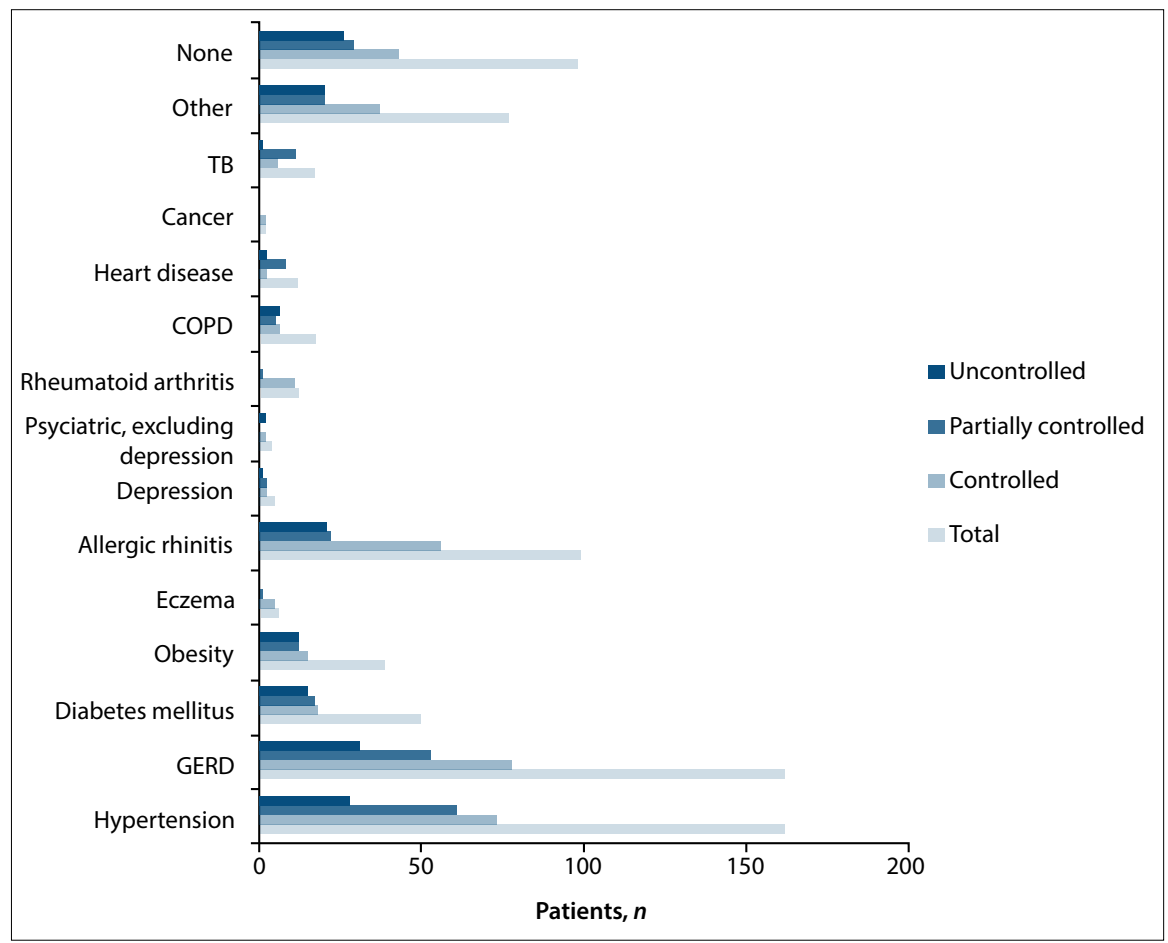

Fig. 1. Comorbidities in the cohort and in the three levels of asthma control. $(T B=$ tuberculosis)

likely to experience (OR 8.16 for admissions per year, and OR 2.5 for admissions in a lifetime). In keeping with a study conducted in the Western Cape, ${ }^{[12]}$ about 1 in 5 patients (23\%) were admitted in the prior year for asthma-related morbidity. If one examines data per lifetime, 59\% (209/352) of patients had at least one admission to hospital for asthma-related morbidity. This reiterates the importance of prior hospital admission as a marker for suboptimal asthma control.

Predictably, there were significant differences in the number of exacerbations of asthma as measured by presentations to the Emergency Department, with the lowest numbers occurring in the controlled group when compared with either the partially controlled or uncontrolled groups. The statistically significantly increased likelihood for the uncontrolled group to receive both inhaled and oral CSs may be a marker for more severe asthma, or reflect a poorer inhaler technique.

Inhaler technique was documented by the attending physician in only $57.1 \%$ of patients. There was no correlation between the level of asthma control and whether the attending doctor checked inhaler technique; neither was there evidence that those patients who were poorly controlled had their inhaler technique checked more frequently than those who were well controlled. One could argue that this may be one of the reasons why these patients were poorly controlled. The lack of documentation that the inhaler technique had been checked in these patients is a disappointing result for an aspect of management which is critical for good asthma control, and is included in recommendations to improve asthma control. ${ }^{[12]}$ Attending physicians need to be fastidious about checking inhaler technique and recording it at every visit.

Although the quality of the inhaler technique was recorded in only $57 \%$ of patients, a significant difference was seen when compared with the level of asthma control. The majority $(75.7 \%)$ of patients whose inhaler technique was checked had fair to good technique, with an OR of 2.41 when compared with the number in the uncontrolled group of patients.

There was a median of one comorbidity in all three groups of control. Interestingly, despite the increased use of oral CSs in the uncontrolled group, there was no significant increase in CS-associated diseases, for example diabetes, obesity and hypertension. As has been found internationally, ${ }^{[13]}$ GERD was noted in our study population. However, our figure of $33 \%$ of asthmatics with GERD is relatively low and there was no observed increase in its prevalence within either the uncontrolled or the partially controlled groups compared with the controlled group. This is difficult to interpret, as not all patients were subjected to gastroscopy or barium swallows in order to document the presence of GERD, neither were symptoms specifically recorded on our questionnaire. It may be of interest to closely interrogate and examine the patients in the two poorly controlled groups for GERD, although the contribution of concomitant GERD with asthma may vary according to the asthma phenotype, and not with the level of control. ${ }^{[13]}$

Allergic rhinitis was found in only $20.3 \%$ of the cohort, considerably lower than the $67 \%$ found in a Japanese study. ${ }^{[13]}$ Allergic rhinitis was more commonly diagnosed in the controlled group compared with the uncontrolled group $(p=0.023)$, in conflict with the Japanese data which described allergic rhinitis as an aggravating factor for poorer control. ${ }^{[13]}$ However, allergic rhinitis may be under-diagnosed in the poorly controlled groups.

Rheumatoid arthritis was more frequent in those patients with controlled asthma compared with uncontrolled $(p=0.018)$ and partially controlled $(p=0.032)$, suggesting that it may be protective in the control of asthma. Possible explanations for this include the healthy user bias, or that the immunosuppressive drugs used to treat rheumatoid arthritis, particularly methotrexate, may have a beneficial effect in asthma.

\section{Conclusion}

In this population of mostly middle-aged female asthmatics, less than half the patients were well-controlled despite relatively few admissions or exacerbations in the previous year. Control of asthma has a significant impact on the number of exacerbations and admissions during the year, leading to higher healthcare costs in those patients who were not well-controlled. Documentation by clinicians of aspects indicative of asthma control and the routine checking of inhaler technique should be mandatory in order to improve knowledge and highlight awareness of best practice in the management of asthma.

Study limitations

This study had several limitations, because it was a retrospective review, and as such, 
Table 3. Comorbidities in the cohort, and in levels of asthma control

\begin{tabular}{|c|c|c|c|c|c|c|c|c|c|c|}
\hline & \multirow{2}{*}{$\begin{array}{l}\text { Total } \\
\text { cohort } \\
(N=487) \\
n(\%)\end{array}$} & \multirow{2}{*}{$\begin{array}{l}\text { Controlled } \\
(N=224), \\
n(\%)\end{array}$} & \multirow{2}{*}{$\begin{array}{l}\text { Partially } \\
\text { controlled } \\
(N=150), \\
n(\%)\end{array}$} & \multirow{2}{*}{$\begin{array}{l}\text { Uncontrolled } \\
(N=113), \\
n(\%)\end{array}$} & \multicolumn{3}{|c|}{ Controlled v. uncontrolled } & \multicolumn{3}{|c|}{$\begin{array}{c}\text { Controlled v. partially } \\
\text { controlled }\end{array}$} \\
\hline & & & & & $p$-value & OR & 95\% CI & $p$-value & OR & $95 \% \mathrm{CI}$ \\
\hline Hypertension & $162(33.3)$ & $73(32.6)$ & $61(40.7)$ & $28(24.8)$ & 0.18 & 0.68 & $0.41-1.13$ & 0.14 & 1.42 & $0.92-2.18$ \\
\hline $\begin{array}{l}\text { Gastro- } \\
\text { oesophageal } \\
\text { reflux }\end{array}$ & $162(33.3)$ & $78(34.8)$ & $53(35.3)$ & $31(27.4)$ & 0.21 & 0.71 & $0.43-1.16$ & 1.00 & 1.02 & $0.66-1.58$ \\
\hline $\begin{array}{l}\text { Diabetes } \\
\text { mellitus }\end{array}$ & $50(10.3)$ & $18(8.0)$ & $17(11.3)$ & $15(13.3)$ & 0.18 & 1.75 & $0.85-3.62$ & 0.37 & 1.46 & $0.73-2.94$ \\
\hline Obesity & $39(8.0)$ & $15(6.7)$ & $12(8.0)$ & $12(10.6)$ & 0.30 & 1.66 & $0.74-3.67$ & 0.79 & 1.21 & $0.55-2.67$ \\
\hline Allergic rhinitis & $99(20.3)$ & $56(25.0)$ & $22(14.7)$ & $21(18.6)$ & 0.24 & 0.68 & $0.39-1.20$ & 0.023 & 0.52 & $0.30-0.89$ \\
\hline Depression & $5(1.0)$ & $2(0.9)$ & $2(1.3)$ & $1(0.9)$ & 1.00 & 0.99 & $\begin{array}{l}0.089- \\
11.05\end{array}$ & 1.00 & 15.00 & $0.21-10.77$ \\
\hline $\begin{array}{l}\text { Rheumatoid } \\
\text { arthritis }\end{array}$ & $12(2.5)$ & $11(4.9)$ & $1(0.7)$ & $0(0)$ & 0.018 & - & - & 0.032 & 0.13 & $0.017-1.02$ \\
\hline COPD & $17(3.5)$ & $6(2.7)$ & $5(3.3)$ & $6(5.3)$ & 0.35 & 2.04 & $0.64-6.47$ & 0.76 & 1.25 & $0.38-4.18$ \\
\hline Heart disease & $12(2.5)$ & $2(0.9)$ & $8(5.3)$ & $2(1.8)$ & 0.60 & 2.00 & $\begin{array}{l}0.28- \\
14.39\end{array}$ & 0.017 & 6.25 & $1.31-29.87$ \\
\hline Cancer & $2(0.4)$ & $2(0.9)$ & $0(0)$ & $0(0)$ & 0.55 & - & - & 0.52 & - & - \\
\hline $\begin{array}{l}\text { Psychiatric } \\
\text { disease }\end{array}$ & $4(0.8)$ & $2(0.9)$ & $0(0)$ & $2(1.8)$ & 0.60 & 2.00 & $\begin{array}{l}0.28- \\
14.39\end{array}$ & 0.52 & - & - \\
\hline $\begin{array}{l}\text { Previous } \\
\text { tuberculosis }\end{array}$ & $17(3.5)$ & $5(2.2)$ & $11(7.3)$ & $1(0.9)$ & 0.45 & 0.39 & $\begin{array}{l}0.045- \\
3.39\end{array}$ & 0.02 & 3.47 & $1.18-10.19$ \\
\hline HIV & $34(7.0)$ & $14(6.3)$ & $13(8.7)$ & $7(6.2)$ & 0.50 & 1.26 & $0.73-2.18$ & 0.92 & 1.01 & $0.60-1.70$ \\
\hline Eczema & $6(1.2)$ & $5(2.2)$ & $1(0.7)$ & $0(0)$ & - & - & - & 0.50 & 1.42 & $0.65-3.12$ \\
\hline Other & 77 (15.8) & 37 (16.5) & $20(13.3)$ & $20(17.7)$ & 0.92 & 1.09 & $0.60-1.98$ & 0.49 & 0.78 & $0.43-1.40$ \\
\hline None & $98(20.1)$ & $43(19.2)$ & $29(19.3)$ & $26(23.0)$ & - & - & - & - & - & - \\
\hline
\end{tabular}

accurate record-keeping was a concern, as demonstrated by the large number of data points missing, particularly in the fields of checking the inhaler technique, and lung functions results.

There was no characterisation of the phenotype of asthma as a predictor for control.

Acknowledgements. Our thanks to the staff and patients at ROPD for their willingness to help, and to Leporogo Academic Services for their assistance with compiling the study.

\section{References}

1. V Gemert F, van der Molen T, Jones R, Chavannes N. The impact of asthma and COPD in sub-Saharan Africa. Prim Care Respir J 2011;20(3):240-248.

2. Slejko JF, Ghushchyan VH, Sucher B, et al. Asthma control in the United States, 2008 - 2010: Indicators of poor asthma control. J Allergy Clin Immunol 2014;133(6):15791587. [http://dx.doi.org/10.1016/j.jaci.2013.10.028]

3. Yawn BP. Factors accounting for asthma variability: Achieving optimal symptom control for individual patients. Prim Care Respir J 2008;17(3):138-147.

4. Lalloo UAG, Wong M, Abdool-Gaffar S, et al. Guidelines for the management of chronic asthma in adolescents and adults. SA Fam Pract 2007;49(5):19-31.
5. Hansen S, Probst-Hensch N, Keidel D, et al. Gender differences in adult-onset asthma: Results from the Swiss SAPALDIA cohort study. Eur Respir J 2015;46(4):1011-1020. [http://dx.doi.org/10.1183/13993003.02278-2014]

6. Ehrlich RI, White N, Norman R, et al. Wheeze, asthma diagnosis and medication use: A national adult survey in a developing country. Thorax 2005;60(11):895-901. [http:// dx.doi.org/10.1136/thx.2004.030932]

7. Corrado A, Renda T, Polese G, Rossi A. Assessment of asthma control: The SERENA study. Respir Med 2013;107(11):1659-1666. [http://dx.doi.org/10.1016/j.rmed.2013.08.019]

8. Moore WC, Meyers DA, Wenzel SE, et al. Identification of asthma phenotypes using cluster analysis in the Severe Asthma Research Program. Am J Respir Crit Care Med 2010;181(4):315-323. [http://dx.doi.org/10.1164/rccm.200906-0896OC]

9. Wang Y, Hunt K, Nazreth I, Freemantle N, Petersen I. Do men consult less than women? An analysis of routinely collected UK general practice data. BMJ Open. 2013;3(003320). [http://dx.doi.org/10.1136/bmjopen-2013-003320]

10. Burney P, Jarvis D, Perez-Padilla R. The global burden of chronic respiratory disease in adults. Int J Tuberc Lung Dis 2015;19(1):10-20. [http://dx.doi.org/10.5588/ijtld.14.0446]

11. Gold LS, Yeung K, Smith N, Allen-Ramey FC, Nathan RA, Sullivan SD. Asthma control, cost and race: Results from a national survey. J Asthma 2013;50(7):783-790. [http://dx.doi.org/10.3109/02770903.2013.795589].

12. Mash B, Rhode H, Pather M, et al. Quality of asthma care: Western Cape Province, South Africa. S Afr Med J 2009;99(12):892-896.

13. Ishizuka T, Hisada T, Kamide Y, et al. The effects of concomitant GERD, dyspepsia, and rhinosinusitis on asthma symptoms and FeNO in asthmatic patients taking controller medications. J Asthma Allergy 2014;7:131-139. [http://dx.doi.org/10.2147/JAA.S67062] 